\title{
Communication
}

\section{Non-Hydrostatic Modeling of Waves Generated by Landslides with Different Mobility}

\author{
Ryan P. Mulligan *(D), W. Andy Take and Gemma K. Bullard \\ Department of Civil Engineering, Queen's University, Kingston, ON K7L 3N6, Canada \\ * Correspondence: ryan.mulligan@queensu.ca; Tel.: +1-613-533-6503
}

Received: 18 June 2019; Accepted: 8 August 2019; Published: 10 August 2019

check for updates

\begin{abstract}
Tsunamis are generated when landslides transfer momentum to water, and these waves are major hazards in the mountainous coastal areas of lakes, reservoir, and fjords. In this study, the influence of slide mobility on wave generation is investigated using new: (i) experimental observations; (ii) theoretical relationships; and (iii) non-hydrostatic numerical predictions of the water surface and flow velocity evolution. This is accomplished by comparing landslides with low and high mobility and computing the momentum flux from landslides to water based on data collected in laboratory experiments. These slides have different materials, different impact velocities, different submarine runout distances, and generate very different waves. The waves evolve differently along the length of the waves' flume, and the experimental results are in close agreement with high-resolution phase-resolving simulations. In this short communication, we describe new research on landslide generated waves conducted at Queen's University, Canada, and presented at Coastlab18 in Santander, Spain.
\end{abstract}

Keywords: landslide waves; tsunamis; laboratory experiments; momentum balance; numerical wave modeling

\section{Introduction}

Landslide mobility (LM) describes the velocity and distal reach of the debris from a slide. This is a complex phenomenon of interacting processes that depends on many landslide parameters including the density, porosity, internal shear strength, basal friction, particle collisions, pore pressures, and possible fluidization. Despite this complexity, a slide with a higher LM would have a higher velocity and a longer runout distance at the base of a slope compared with a slide with the same volume but a lower LM. These highly mobile slides that travel long distances are, therefore, more hazardous (e.g., [1]). When a landslide impacts a body of water, momentum is transferred from the sliding mass to the water, generating a wave or series of waves [2]. Unlike the case of tsunamis generation by earthquakes where vertical and horizontal motions of the seafloor cause water displacement [3,4], subaerial landslides generate waves primarily from the streamwise momentum flux or the along-channel component of mass flow into water $[5,6]$. Other experimental studies (e.g., [7,8]) have found relationships between the dependence of the wave energy and maximum wave amplitude on the slide impact velocity and the hill slope angle.

Highly mobile landslides have the potential to be a more severe hazard due to the high speed and longer runout distances that can be affected [9]. The analytical work of [2,10] attempt to capture the proportion of the landslide contributing to the wave using the time and length scales of impact. These scale parameters describe how quickly the submerged mass decelerates after impacting the reservoir, which is a measure of landslide mobility. The influence of changing landslide mobility was indirectly investigated by [11] using positively buoyant particles and a range in landslide porosity. The study found that increasing the landslide porosity results in a decrease in the maximum near-field 
amplitude due to a larger deceleration upon impact. This potentially lends support to the hypothesis that increasing landslide mobility will result in larger wave amplitudes, however, the influence of landslide mobility has yet to be quantified directly.

In the present study, we investigate the influence of landslide mobility on wave generation by postulating that a highly mobile slide carries higher momentum when it is transferred to water and therefore, generates a larger wave. This is accomplished by comparing the waves generated by cases for very different slide materials that include granular material (low LM) and water (high LM). These are selected to be representative of a dry soil or rock landslide (using the granular particles) a mudflow or saturated debris flow (using water). We perform laboratory experiments (Section 2), calculate the theoretical momentum balance (Section 3) and conduct non-hydrostatic numerical simulations of surface elevation and flow velocity evolution (Section 4) to investigate the differences between the landslides with different mobility and the waves they generate. The goal of this paper is to highlight the importance of landslide mobility on the near field wave properties and wave evolution into the far field by a discussion of recent advances in understanding landslide-generated tsunamis from large scale experiments, consideration of the momentum transfer, and a numerical phase-resolving wave propagation model.

\section{Laboratory Experiments}

Experiments were performed in a landslide flume consisting of an $8.23 \mathrm{~m}$ long slope inclined at $30^{\circ}$ to the horizontal to gravitationally accelerate landslides into a $33.0 \mathrm{~m}$ long and $2.1 \mathrm{~m}$ wide horizontal wave flume described in detail by [12], shown in Figure 1. Tests with different mobility were selected as end-member examples in the present study. However, a considerable number of experiments have been conducted by [13], and some of these tests are described by [14]. Material is released from a source volume box at the top of the slope, accelerates down the landslide slope, impacts the water with thickness $s$ and velocity $v_{s}$ where it generates waves, propagates along the flume and runs up the slope at the end of the flume. In the present study, a triangular source volume $V$ of $3 \mathrm{~mm}$ diameter ceramic beads was used as the more collisional landslide material with lower mobility, and a similar volume of water was used as the highly mobile material. The mean water depth $h$ was very similar for both tests, differing by $0.01 \mathrm{~m}$. The landslide and near field wave properties were observed using a system of high-speed cameras, and these slides generate very different waves, as illustrated by the images of the near-field waves in Figure 2. The observational methods and accuracy of data obtained in the experiments are described in detail by $[13,14]$. The water surface was also measured using nine capacitive probes (P1-P9) along the flume that sample at $100 \mathrm{~Hz}$, and the maximum wave amplitudes were $0.09 \mathrm{~m}$ and $0.29 \mathrm{~m}$ at P1 for the low LM and high LM tests, respectively. The fluid velocity was measured $0.012 \mathrm{~m}$ above the flume bottom using an acoustic velocimeter (Nortek Vectrino Profiler) operating at $100 \mathrm{~Hz}$ at station P2.

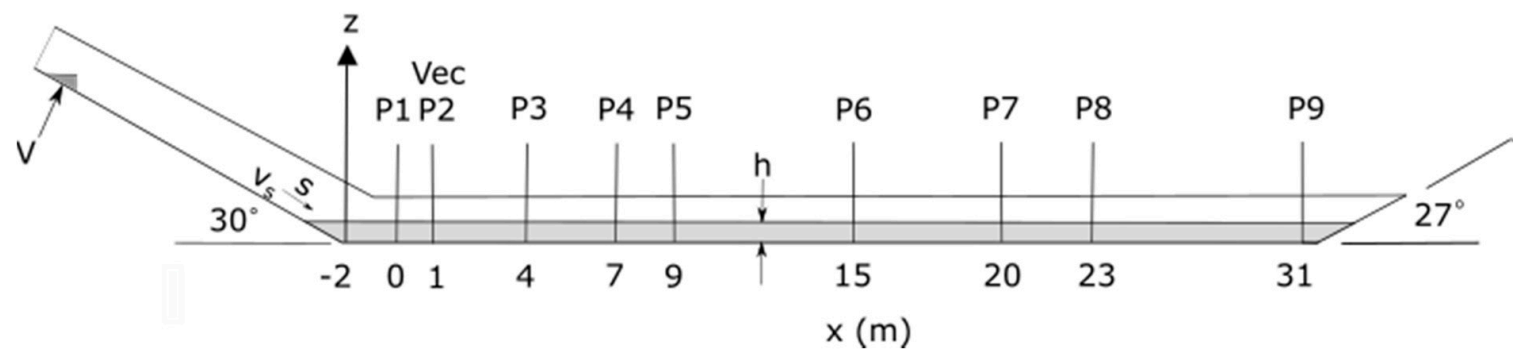

Figure 1. Landslide flume experimental apparatus, indicating the locations of wave probes (P1-P9) and acoustic velocity sensor (Vec). The numerical modeling domain begins at $x=0$, with boundary conditions from observations at P1. 

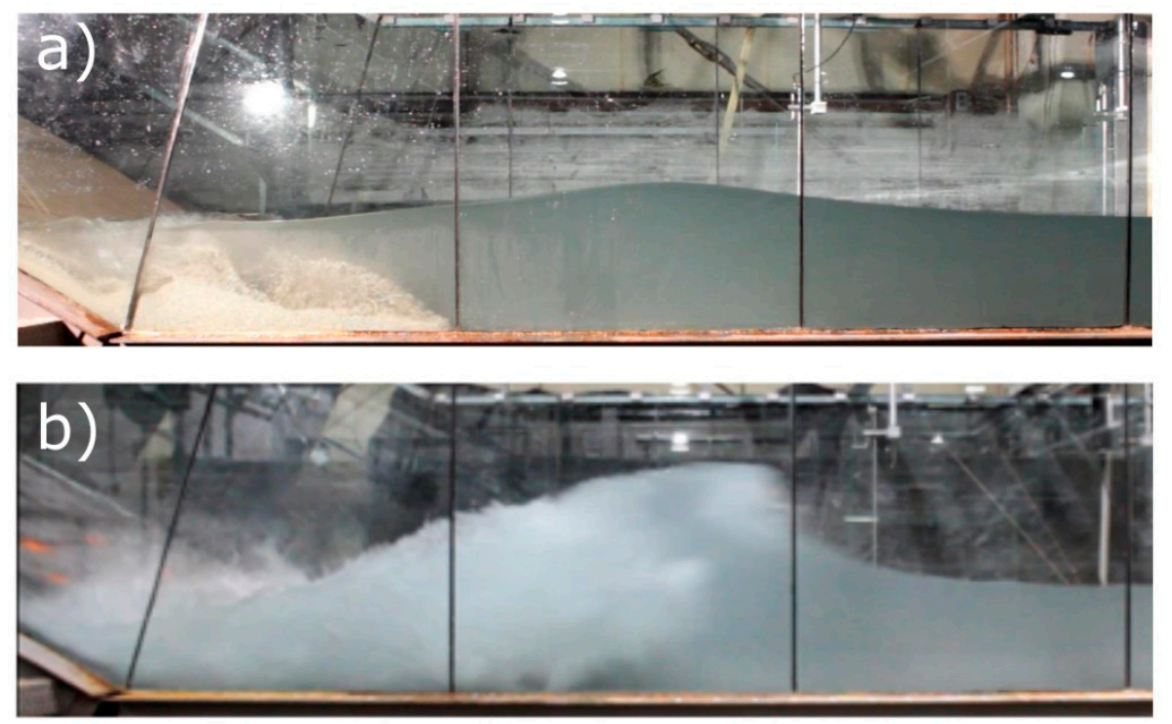

Figure 2. Images of the waves generated by landslides with different mobility: (a) low mobility; (b) high mobility.

\section{Theoretical Momentum Balance}

The generation and propagation of tsunamis are highly complex. However, by considering the momentum balance under idealized conditions, theoretical relationships for the maximum wave amplitude in the near-field zone can be derived [2]. Following this approach, the landslide momentum flux $\left(\boldsymbol{M}_{\boldsymbol{s}}\right)$ can be estimated as

$$
M_{s}=\frac{\rho_{s} s v_{s \cos \alpha}}{\Delta t_{e}}
$$

where the sliding mass with bulk density $\rho_{s}$ impacts the water on slope $\alpha$ at velocity $v_{s}$ parallel to the slope. It has thickness $s$ on impact with the water, and the resulting wave is generated over the effective time $\Delta t_{e}$ that momentum is imparted from the slide to the water [12]. The fluid momentum flux $\left(\boldsymbol{M}_{f}\right)$ is given by:

$$
M_{f}=\frac{\rho g\left(h a_{m}+\frac{1}{2} a_{m}^{2}\right)}{L}
$$

This depends on the maximum wave amplitude $a_{m}$ above the still water level, the initially still water depth $h$, the fluid density $\rho$, gravitational acceleration $g$, and submarine runout length $L$ over which the wave is generated. The idealized momentum flux between the slide $\left(\boldsymbol{M}_{\boldsymbol{s}}\right)$ and the fluid $\left(\boldsymbol{M}_{f}\right)$ is expressed per unit length of the slide and per unit width of the flume in units of $\mathrm{kg} /\left(\mathrm{ms}^{2}\right)$, and this is equivalent to force per unit area $\left(\mathrm{N} / \mathrm{m}^{2}\right)$. In this approach, idealized theoretical equations are developed for landslides with a significant horizontal velocity component on moderate slopes, and are not valid for vertical rockfalls. The vertical fall velocity of a landslide is also important, and this is accounted for in the development of a limiting relationship based on the fluid continuity equation [2].

In the present study, we examined the balance of momentum between the landslide and the fluid at the wave probe closest to the impact region (P1) for the low LM and high LM experiments. The terms in Equations (1) and (2) were evaluated using the bulk landslide properties in Table 1 that were measured using cameras and wave probes. This table provides the experimental conditions and indicates the differences in forcing for the end-member mobility cases, and each experiment results in very different wave characteristics. The time series of water surface elevations at P1 are shown in Figure 3, with the maximum wave amplitude of $0.29 \mathrm{~m}$ for the high LM experiment and a significantly smaller value of $0.09 \mathrm{~m}$ for the low LM experiment. The runout distances were 3.0 and $1.6 \mathrm{~m}$, and the effective times were 0.5 and $1.0 \mathrm{~s}$ for the high and low LM cases, respectively. The value of the momentum terms for these experiments and a larger dataset with varying slide volume and 
reservoir depth are shown in Figure 4. The momentum contained in both the landside and the fluid was greater for the high LM slides compared to the low LM landslides. Overall there was a high correlation for the high mobility slides $(R=0.89$ for 12 tests) and for the low mobility slides $(R=0.92$ for 4 tests), and these values are high considering that other momentum terms, such as dissipation are neglected.

Table 1. Experimental conditions for examples of landslides with different mobility.

\begin{tabular}{ccccccc}
\hline Mobility & $\rho_{\boldsymbol{s}}\left(\mathbf{k g} / \mathbf{m}^{3}\right)$ & $\boldsymbol{V}\left(\mathbf{m}^{\mathbf{3}}\right)$ & $\boldsymbol{v}_{\boldsymbol{s}}(\mathbf{m} / \mathbf{s})$ & $\boldsymbol{s}(\mathbf{m})$ & $h(\mathbf{m})$ & $\boldsymbol{a}_{\boldsymbol{m}}(\mathbf{m})$ \\
\hline low LM (granular) & 1400 & 0.34 & 4.00 & 0.040 & 0.30 & 0.09 \\
high LM (water) & 1000 & 0.30 & 5.38 & 0.043 & 0.31 & 0.29 \\
\hline
\end{tabular}

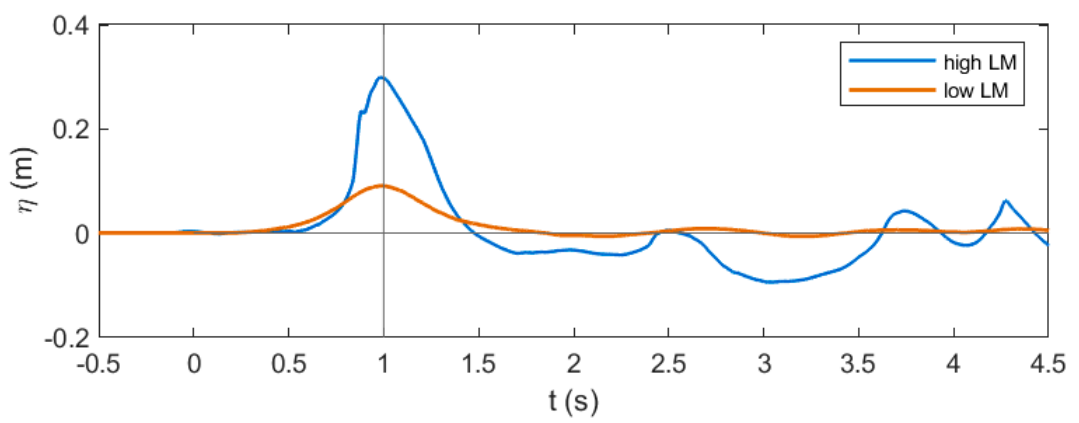

Figure 3. Example time series of water surface elevation near the impact site for landslides with low and high mobility, adjusted such that the maximum amplitude occurs at $t=1 \mathrm{~s}$. These waves were observed at wave probe P1 and correspond to the experimental conditions listed in Table 1.

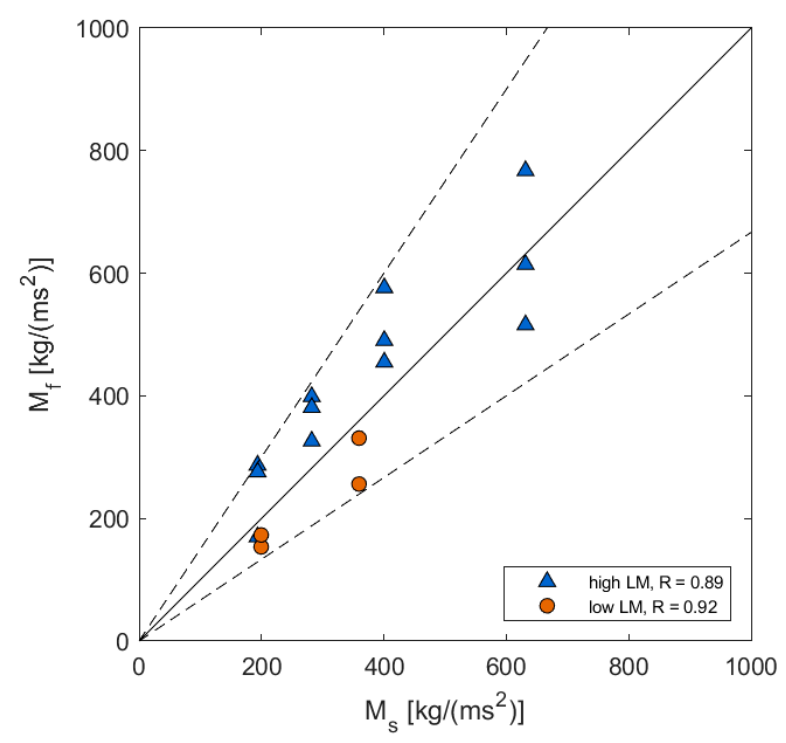

Figure 4. Balance of momentum terms for a set of experiments with waves generated by landslides with low and high mobility. The solid line represents perfect correlation, the dashed lines are $\pm 15 \%$ deviation, and correlation coefficients for each type of slide are shown.

The results indicate that the significantly larger waves in the high LM cases were generated by higher slide impact velocities and the longer submarine runout distances. This greater length provides a larger near-field region over which the momentum is transferred to the water before the wave speed $c$ exceeds the decelerating submarine part of the slide and the wave propagates along the flume. 


\section{Numerical Modelling}

\subsection{Model Set-up}

The numerical model is SWASH (Simulating WAves till SHore), a non-hydrostatic wave-flow model that uses a finite-difference approach to solving the fluid momentum and continuity equations [15] and has been used to simulate surface waves observed in laboratory [16] and field [17] conditions. This phase-resolving wave model includes discretization of the oscillating water column into vertical layers and numerically solves for the vertical pressure gradient, important for simulating propagation and dispersive characteristics of the wave field $[18,19]$. Aligned with a previous study [20] for waves generated by granular landslides, the model was applied in the present study to landslide-generated waves, with new results corresponding to data obtained from new experiments. Here we applied boundary conditions developed from water surface elevation observations from the low LM (granular particles, representing a dry soil or rock landslide) and high LM (water, representing a mudflow or saturated debris flow) experiments. The measurements were made at the first wave probe near the source region, and the model was used to simulate propagation and transformation along the flume. The model grid is shown in Figure 1, with the boundary condition applied at $\mathrm{x}=0 \mathrm{~m}$. The boundary conditions were provided by the water surface elevation measurements at wave probe 1 (P1), and only $\eta$ was as input, and not fluid velocity at or below the surface. Comparison between measurements and model results were made at the other wave probe locations (P1-P9). The horizontal grid spacing was $0.10 \mathrm{~m}$, and the model used 20 layers in the vertical direction. Important processes in the model that control the wave transformation and evolution are horizontal mixing, vertical mixing, breaking, and bottom friction.

\subsection{Model Results}

The simulated water surface elevations are compared with laboratory wave probe observations in Figures 5 and 6 for the low LM and high LM cases, respectively. The results indicate that the different landslide mobility generated waves with very different initial shapes that also evolved differently as they propagate away from the landslide source region. The low LM case had a smaller initial wave (Figure 5a) that propagates away from the source with little change in amplitude or shape along the flume (Figure $5 \mathrm{~b}-\mathrm{f}$ ). The model results indicate that for the low LM slide, only bottom friction influences the wave evolution, with equivalent results obtained when other processes were turned off (horizontal mixing, vertical mixing, breaking). In contrast, the much larger wave in the high LM case (Figure 6a) significantly changes in amplitude and shape along the flume (Figure 6b-f). Despite the general agreement, this case was more difficult to simulate, and the amplitude, timing, and shape were not in perfect agreement with the observations. Small differences in the observed and simulated water surface were evident, particularly in the high mobility case, likely due to the high degree of non-linearity and the complexity of wave breaking. In the high mobility case, more complex fluid processes were actively changing the wave (horizontal mixing, vertical mixing, wave breaking, bottom friction) and were needed to simulate the wave evolution. 

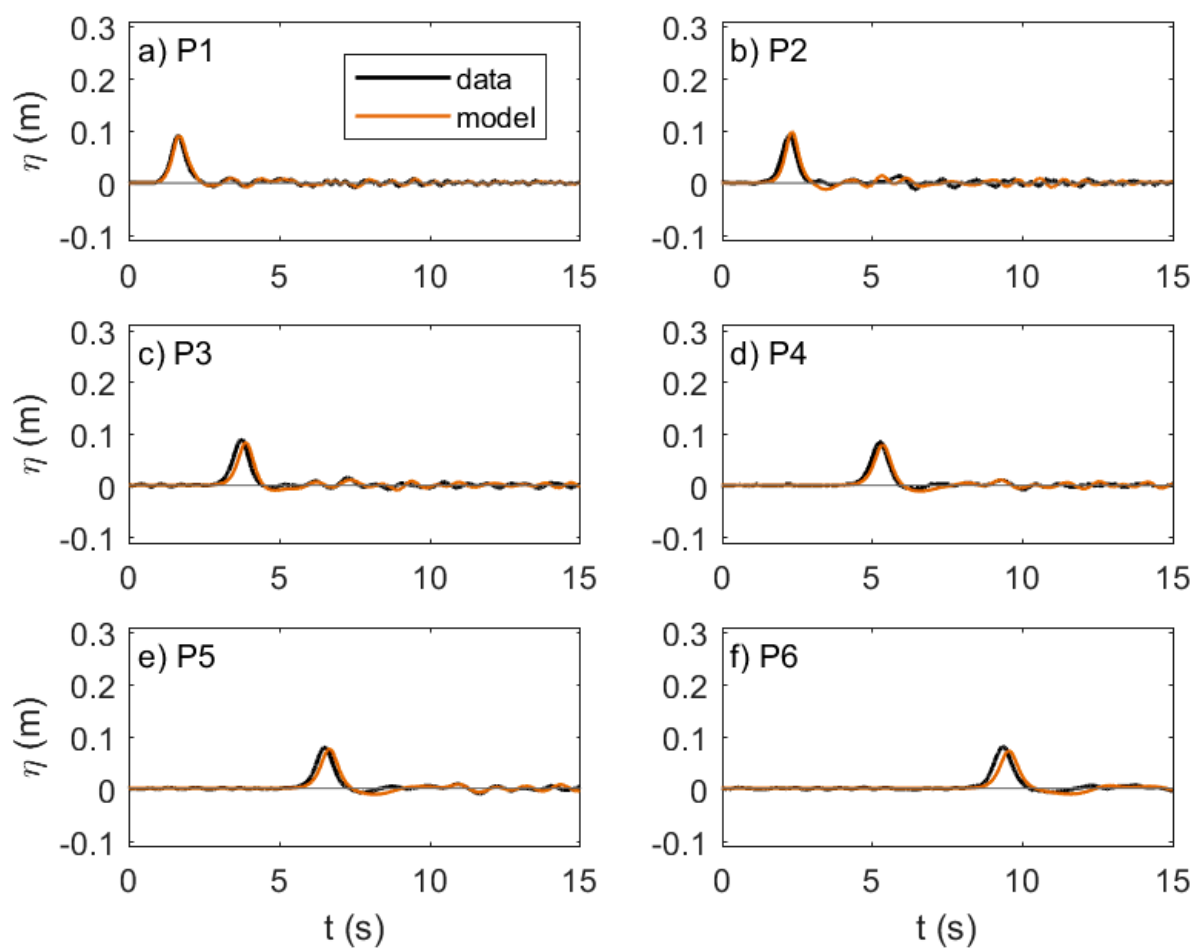

Figure 5. Water surface elevation time series for the low landside mobility case from experimental observations and numerical simulation. Time $t=0 \mathrm{~s}$ is referenced to the slide impact time. Wave probe sites shown in Figure 1 are: (a) P1; (b) P2; (c) P3; (d) P4; (e) P5; and (f) P6.
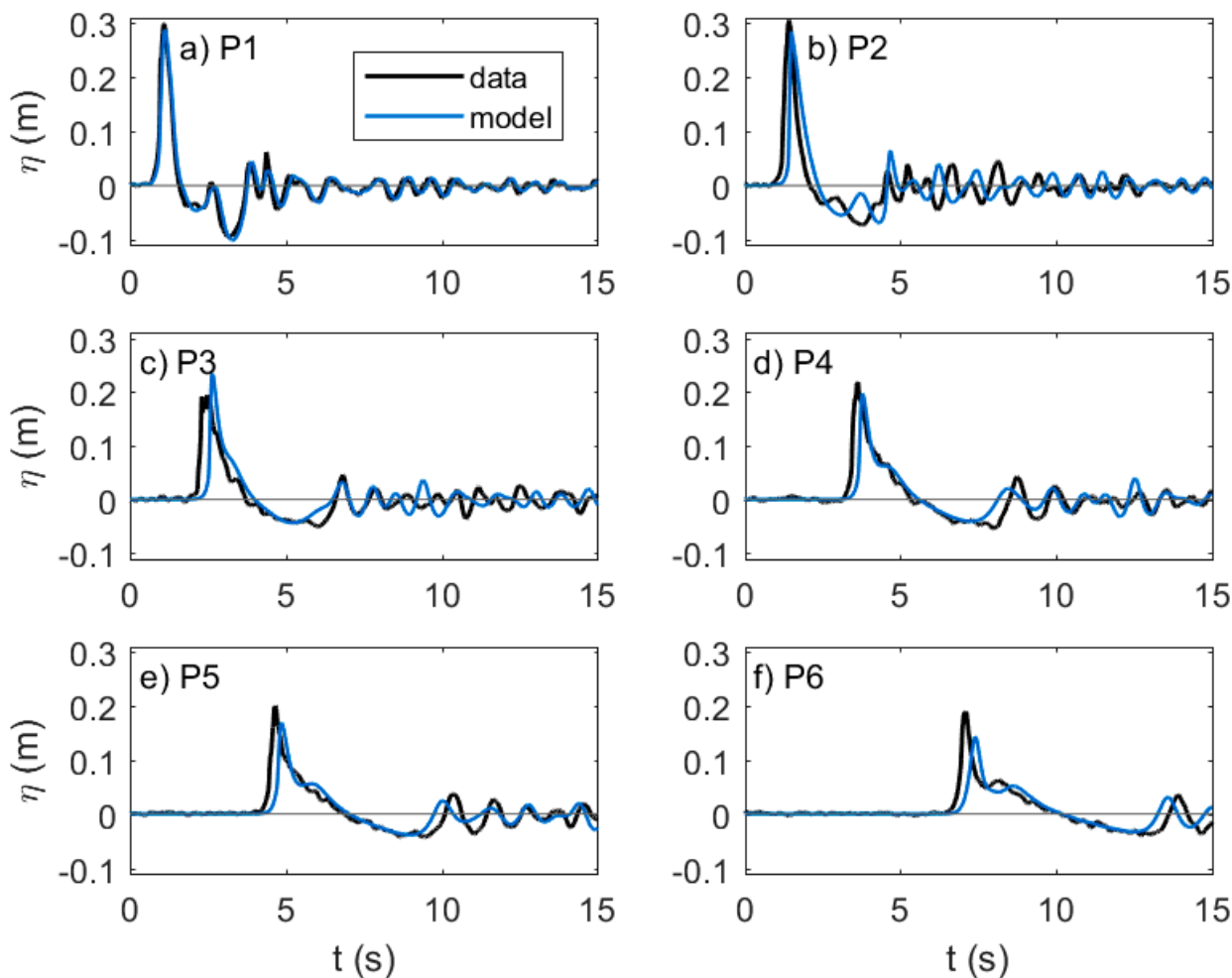

Figure 6. Water surface elevation time series for the high landside mobility case from experimental observations and numerical simulation. Time $t=0 \mathrm{~s}$ is referenced to the slide impact time. Wave probe sites shown in Figure 1 are: (a) P1; (b) P2; (c) P3; (d) P4; (e) P5; and (f) P6. 
Near-bed velocity measurements were made at P2, and the raw data has been smoothed using a low-pass Butterworth filter. The smoothed observations are shown in Figure $7 \mathrm{a}$ with the model results for the lowest vertical layer. The data and model are in fairly close agreement, particularly with the timing of the fluid velocity for the first and largest wave in the train. The amplitude was over-predicted by the model by about $20 \%$, but only for a brief time at the leading edge of the wave. A second peak in velocity at $t=2.8 \mathrm{~s}$ was due to the arrival of the submarine bubble plume flow at the sensor. Since only the water surface elevation was prescribed as the boundary condition, this was not simulated by the model. Further experiments to collect velocity measurements and continue numerical modeling is the subject of ongoing research. The results shown in Figure 7a have small oscillations following the higher velocity fluctuation of the leading wave. It is important to note that in time, small waves follow the leading wave and therefore, occur after it (e.g., $t>6 \mathrm{~s}$ ). These waves, measured at site P2 near the landslide slope, were not influenced by reflection from the far end of the flume as it takes reflected waves $30-35 \mathrm{~s}$ to arrive back to this location. The simulated horizontal velocity field is shown in Figure $7 \mathrm{~b}$ over the vertical profile, indicating the high positive along-channel flow at the wave crest followed by the longer duration and weaker current associated with the trough.
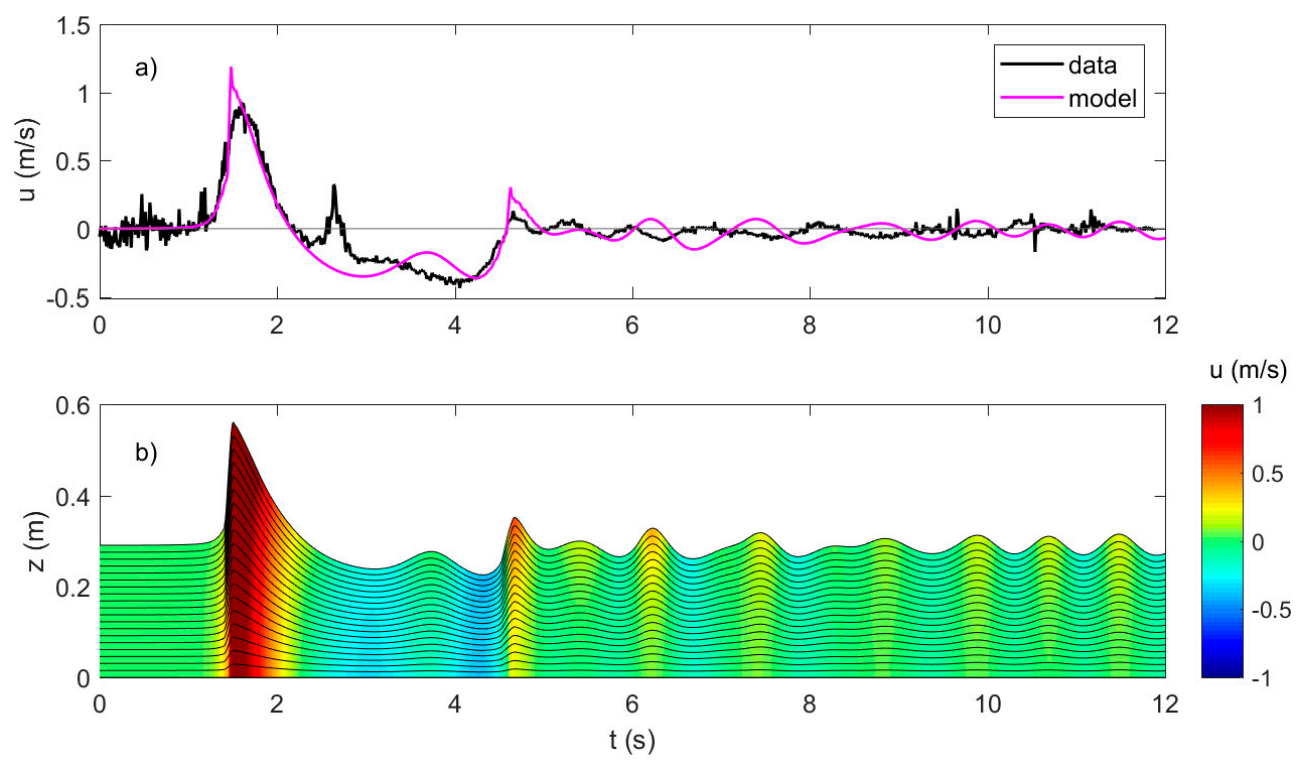

Figure 7. Along-flume fluid velocity time series at probe P2 during the wave passage for the high landside mobility case: (a) observed and predicted near-bottom velocity; (b) simulated water surface elevation and color contours of horizontal velocity, with black lines indicating the vertical grid.

\section{Summary and Conclusions}

This short communication provides new insight for predicting landslide waves by combining results from experimental observations, theoretical relationships, and non-hydrostatic numerical modeling. We investigated the role of landslide mobility, the combination of different materials and landslide behavior that controls the speed and impact properties, on the generation of waves by comparing two cases with different mobility. The larger wave was forced by the higher impact velocity and the longer submarine runout distance from the slide with high mobility, as greater momentum was transferred from the slide to the water over this larger length scale. The results indicated that the landslide with low mobility had a smaller initial wave that propagates away from the source with little change in amplitude or shape along the flume, and in contrast, the much larger wave generated by the high mobility landslide significantly evolved in amplitude and shape with distance from the region of impact. Overall, landslide mobility plays a major role in determining the size of the near-field wave and therefore, also influences its evolution with distance from the impact site due to breaking and fluid mixing. Using the combination of large-scale laboratory experiments and other numerical methods, 
the complex process of wave generation by landslides can be even more accurately quantified and better understood. Future research could focus on the near-field velocity with new experiments and numerical modeling, as this would lead to a more refined boundary condition for simulating landslide waves in coastal environments.

Author Contributions: Conceptualization, R.P.M., W.A.T., G.K.B.; methodology, R.P.M., W.A.T., G.K.B.; laboratory experiments, G.K.B.; numerical modelling, R.P.M.; writing, reviewing and editing, R.P.M., W.A.T., G.K.B.; funding, R.P.M., W.A.T.

Funding: This research was funded by the Natural Science and Engineering Research Council of Canada (NSERC) Discovery Grant programs of the first author [RGPIN/04043-2018] and the second author [RGPIN/04245-2015]. The design and construction of the large-scale landslide flume was funded by the Canada Foundation for Innovation.

Conflicts of Interest: The authors declare no conflicts of interest.

\section{References}

1. Legros, F. The mobility of long-runout landslides. Eng. Geol. 2002, 63, 301-331. [CrossRef]

2. Mulligan, R.P.; Take, W.A. On the transfer of momentum from a granular landslide to a water wave. Coast. Eng. 2017, 125, 16-22. [CrossRef]

3. Tanioka, Y.; Satake, K. Tsunami generation by horizontal displacement of ocean bottom. Geophys. Res. Lett. 1996, 23, 861-864. [CrossRef]

4. Fujiwara, T.; Kodaira, S.; No, T.; Kaiho, Y.; Takahashi, N.; Kaneda, Y. The 2011 Tohoku-Oki earthquake: Displacement reaching the trench axis. Science 2011, 334, 1240. [CrossRef] [PubMed]

5. Zweifel, A.; Hager, W.H.; Minor, H.-E. Plane impulse waves in reservoirs. J. Waterw. Port Coast. Ocean Eng. 2006, 132, 358-368. [CrossRef]

6. Heller, V.; Hager, W.H. Wave types of landslide generated impulse waves. Ocean Eng. 2011, 38, 630-640. [CrossRef]

7. Fritz, H.M.; Hager, W.H.; Minor, H.E. Near field characteristics of landslide generated impulse waves. J. Waterw. Port Coast. Ocean Eng. 2004, 130, 287-302. [CrossRef]

8. Ataie-Ashtiani, B.; Nik-Khah, A. Impulsive waves caused by subaerial landslides. Environ. Fluid Mech. 2008, 8, 263-280. [CrossRef]

9. Iverson, R.M.; George, D.L.; Allstadt, K.; Reid, M.E.; Collins, B.D.; Vallance, J.W.; Schilling, S.P.; Godt, J.W.; Cannon, C.M.; Magirl, C.S.; et al. Landslide mobility and hazards: Implications of the 2014 Oso disaster. Earth Planet. Sci. Lett. 2015, 412, 197-208. [CrossRef]

10. Zitti, G.; Ancey, C.; Postacchini, M.; Brocchini, M. Impulse waves generated by snow avalanches falling into lakes. In Proceedings of the 36th IAHR World Congress, The Hague, The Netherlands, 28 June-3 July 2015.

11. Lindstrøm, E.K. Waves generated by subaerial slides with various porosities. Coast. Eng. 2016, 116, 170-179. [CrossRef]

12. Miller, G.S.; Take, W.A.; Mulligan, R.P. Tsunamis generated by long and thin granular landslides in a large flume. J. Geophys. Res. Oceans 2017, 122, 653-668. [CrossRef]

13. Bullard, G.K. Wave Characteristics of Tsunamis Generated by Landslides of Varying Size and Mobility. Ph.D. Thesis, Queen's University, Kingston, ON, Canada, 2018; 145p.

14. Bullard, G.K.; Mulligan, R.P.; Take, W.A. An enhanced framework to quantify the shape of impulse waves using asymmetry. J. Geophys. Res. Oceans 2019, 124. [CrossRef]

15. Zijlema, M.; Stelling, G.; Smit, P.B. SWASH: An operational public domain code for simulating wave fields and rapidly varied flows in coastal waters. Coast. Eng. 2011, 58, 992-1012. [CrossRef]

16. Rijnsdorp, D.P.; Smit, P.B.; Zijlema, M. Non-hydrostatic modelling of infragravity waves under laboratory conditions. Coast. Eng. 2014, 85, 30-42. [CrossRef]

17. Gomes, E.R.; Mulligan, R.P.; Brodie, K.L.; McNinch, J.E. Bathymetric control on the spatial distribution of wave breaking in the surf zone of a natural beach. Coast. Eng. 2016, 116, 180-194. [CrossRef]

18. Smit, P.; Zijlema, M.; Stelling, G. Depth-induced wave breaking in a non-hydrostatic, near-shore wave model. Coast. Eng. 2013, 76, 1-16. [CrossRef] 
19. Smit, P.; Janssen, T.; Holthuijsen, L.; Smith, J. Non-hydrostatic modeling of surf zone wave dynamics. Coast. Eng. 2014, 83, 36-48. [CrossRef]

20. Mulligan, R.P.; Take, W.A.; Miller, G.S. Propagation and runup of tsunamis generated by gravitationally accelerated granular landslides. In Proceedings of the Coastlab16, Ottawa, ON, Canada, 10-13 May 2016. 